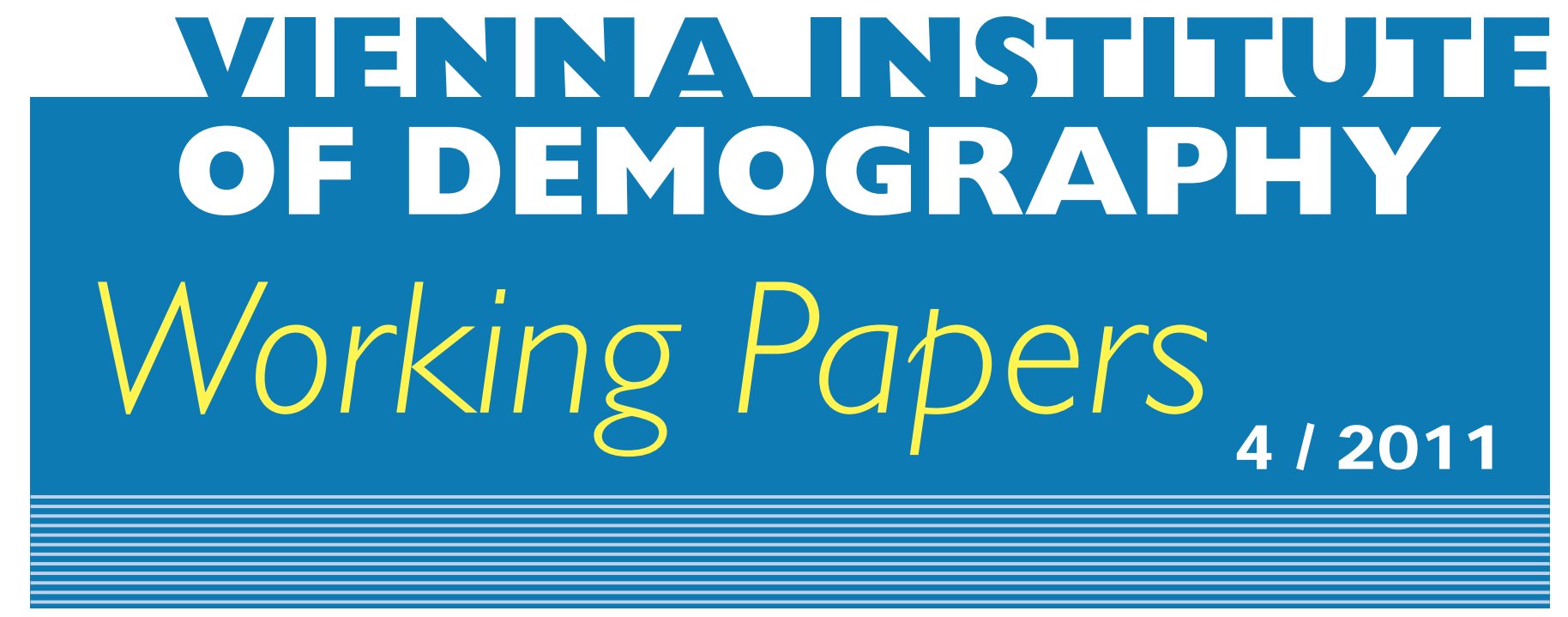

Fernando Riosmena, M aria W inkler-Dworak, Alexia Prskawetz, and Gustav Feichtinger

\title{
The Impact of Policies Influencing the Demography of Age-structured Populations: Lessons from Academies of Sciences
}

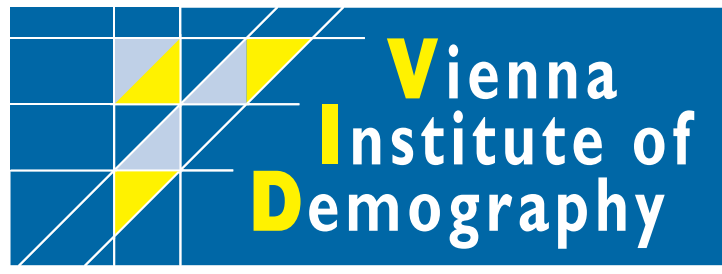

Vienna Institute of Demography Austrian Academy of Sciences

Wohllebengasse 12-14

A-I040 Vienna Austria

E-Mail:vid@oeaw.ac.at

Website: www.oeaw.ac.at/vid 


\begin{abstract}
In this paper, we discuss the role of a diverse set of policies aimed at regulating the number and age structure of elections on the size and age structure of five European Academies of Sciences, namely the Austrian, Berlin-Brandenburg, Russian and Norwegian academies and the Royal Society. We show the recent pace of ageing and the degree of variation in policies across them and discuss the implications of different policies across these academies, regulating the number of elections and influencing their age structure. We illustrate the potential effect of different election regimes (fixed vs. linked) and age structures of election (younger vs. older) by contrasting the steady-state and transient dynamics of different projections of Full Members in each academy into 2070 and measuring the size and agecompositional effect of changing a given policy relative to a status quo policy scenario. Our findings suggest that academies with linked intake (i.e., where the size of the academy below a certain age is fixed and the number of elections is set to the number of members becoming that age) may be a more efficient approach to curb growth without suffering any ageing tradeoffs relative to the faster growth of academies electing a fixed number of members per year. We further note that academies need to take into consideration their current age structure before enacting this type of intake regime as the potential of (negative) momentum could be sizable.
\end{abstract}

\title{
Keywords
}

Ageing, learned societies, cohort-component projections, election policies

\section{Authors}

Fernando Riosmena, Population Program, Institute of Behavioral Science and Department of Geography, University of Colorado at Boulder. Corresponding author: Fernando.Riosmena@colorado.edu

Maria Winkler-Dworak, Vienna Institute of Demography (Austrian Academy of Sciences) and Wittgenstein Centre for Demography and Global Human Capital.

Alexia Prskawetz, Institute of Mathematical Methods in Economics (Vienna University of Technology) and Vienna Institute of Demography (Austrian Academy of Sciences) and Wittgenstein Centre for Demography and Global Human Capital.

Gustav Feichtinger, Institute of Mathematical Methods in Economics (Vienna University of Technology) and Vienna Institute of Demography (Austrian Academy of Sciences) and Wittgenstein Centre for Demography and Global Human Capital.

\section{Acknowledgements}

We gratefully acknowledge funding from the Austrian Science Fund Project No. P20408-G14 ("Age Structured Populations with Fixed Size"). Moreover, we are thankful to the administrations of the Austrian Academy of Sciences, the Berlin-Brandenburg Academy of Sciences, the Norwegian Academy of Sciences and Henri Leridon for kindly providing us with data on the members of the academies. 


\title{
The Impact of Policies Influencing the Demography of Age- structured Populations: Lessons from Academies of Sciences
}

\author{
Fernando Riosmena, Maria Winkler-Dworak, Alexia Prskawetz, Gustav Feichtinger
}

\section{Introduction}

Population ageing is transforming the demographic makeup of many nations (e.g. Bongaarts 2009; Uhlenberg 2009). While longstanding patterns of low fertility have been major contributors for the observed trends, significant reductions in adult mortalityincluding the oldest-old ages - have had and will continue to have a nontrivial impact on the age structure (Kim and Schoen 1997; Preston et al. 1989; Rowland 1996). ${ }^{1}$ Under prevailing systems of social security, labour market policies and institutional frameworks in most industrialised countries these demographic developments may pose economic challenges and could endanger the sustainability of economic growth (see works in Prskawetz et al. 2008).

The pace of ageing is especially rapid for structured organisations like armies, universities and academies of sciences - the case under study herein. These institutions have aged considerably in the last few years (Cohen 2009; Van de Kaa and de Roo 2006). Figure 1 illustrates the rapid ageing of these organisations by showing trends in the mean age of the population in five European academies of sciences. These academies currently have mean ages above $68,{ }^{2}$ a result of a rapid, secular trend due to both ageing from the top and bottom. Academician longevity, already remarkable throughout history (Andreev and Jdanov 2007; Cohen 2009; Houdaille 1980; Jdanov and Andreev 2009; Leridon 2005; Matthiesen 1998; van de Kaa and de Roo 2008; Winkler-Dworak 2008; Winkler-Dworak 2011), has continued to increase over the past few decades (Andreev and Jdanov 2007; Jdanov and Andreev 2009; Van de Kaa and de Roo 2008; Winkler-Dworak 2008). Further, this has been compounded by an upward trend in the mean age at election in many academies, as shown in Figure 2.

\footnotetext{
${ }^{1}$ Even if milder, the consequences of ageing 'from the top' tend to be more immediate than those of ageing brought about by decreasing fertility.

${ }^{2}$ Note that the mean age of the Berlin-Brandenburg Academy of Sciences is somewhat lower. This can be explained by the fact that the academy was recently re-founded and the age distribution of new members is generally younger than for the other academies.
} 
Figure 2

Mean age of full members by academy and year

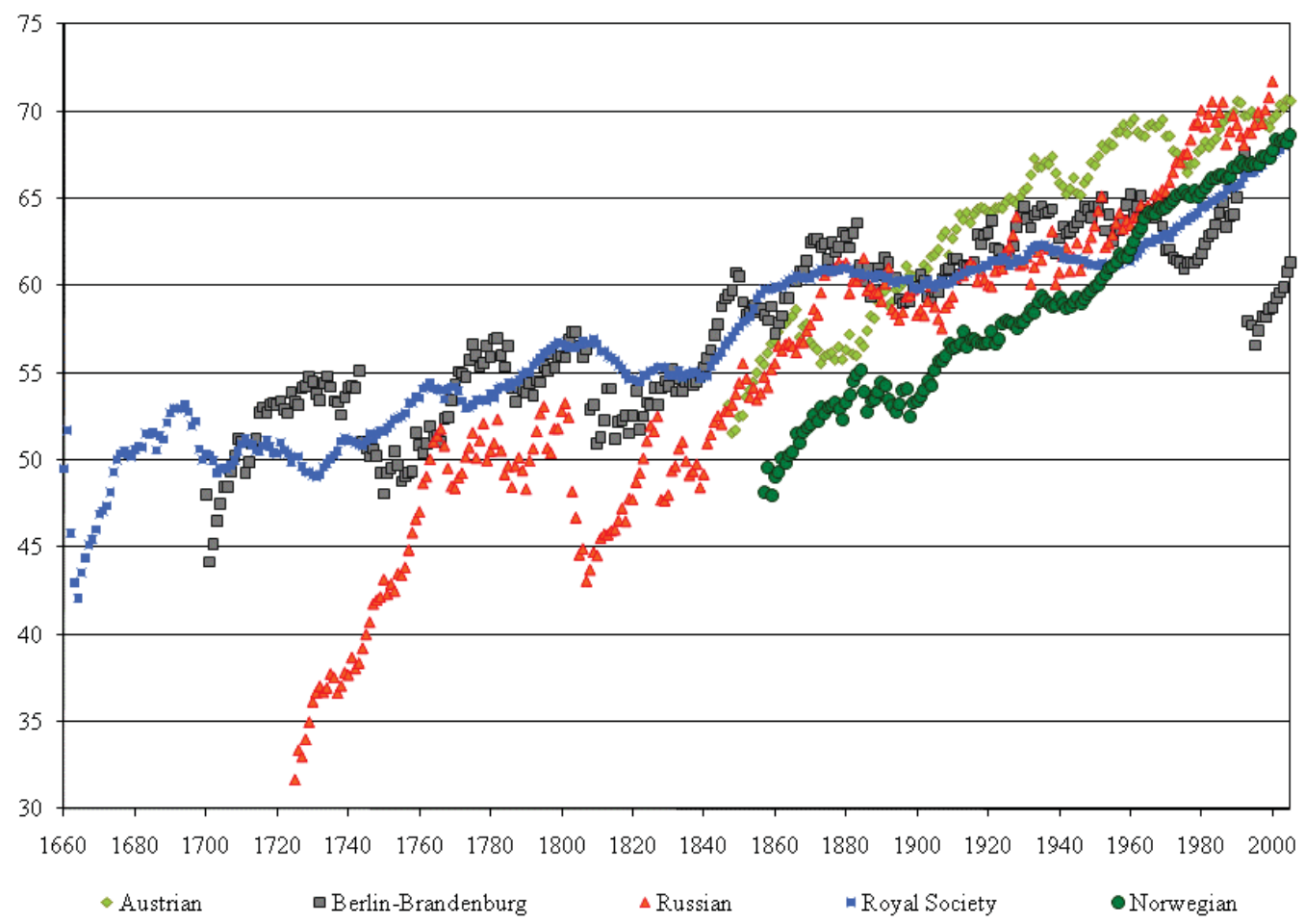

\section{Figure 1}

Mean age at election of full members by academy and period

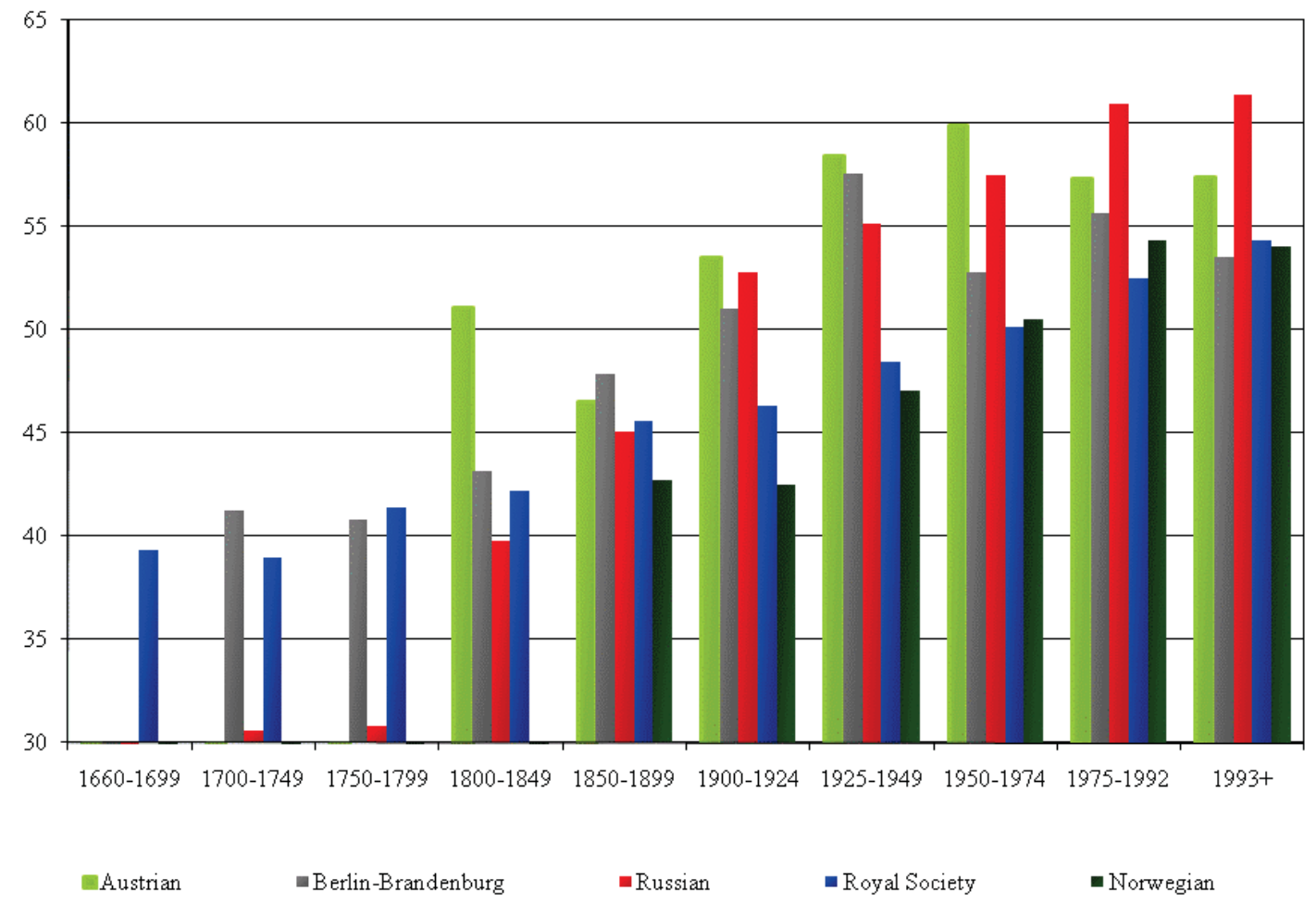


As compared to nation states, the age structure of these organisations is especially sensitive to changes in survival and intake. While this poses a challenge, academies are also better equipped to regulate their pace of ageing through several policies affecting the number and, with more difficulty, the age structure of newly-elected members. ${ }^{3}$ In practice, the byelaws of most academies regulate growth either by setting the number of elections per year to a fixed number or allowing them to fluctuate while linking them to a given target, such as the total number of members below a certain age. The Austrian, Berlin-Brandenburg and Norwegian academies are a case of the latter, having set a maximum number of members below 70, 68 and 67, respectively. Assuming mortality below this age is negligible, this policy implies that the number of elections will be equal to the number of members reaching that age. ${ }^{4}$ However, the younger the newly elected members are, the longer it takes until these members reach the age limit. Thus, the age structure of elected members will be a crucial component determining the future age structure and the future number of elections in an academy under these conditions (Dawid et al. 2009; Feichtinger et al. 2007).

In addition, other considerations could affect the age structure of elections and, in turn, that of an academy. Although not formally stated in their byelaws, some academies elect most of their 'full' members (i.e. those with voting rights and, in some cases, full access to other benefits) from a pool of another membership category, generally a 'corresponding' membership, thus de facto serving as full-membership 'candidacy'. The age structure of election may be affected by the existence of a corresponding status, as it may add a waiting time before election to full member, as we show below.

Given the sensitivity of academies to these policies, previous studies have determined the optimal recruitment strategies to keep an academy 'young' (Dawid et al. 2009; Feichtinger et al. 2007; Feichtinger et al. 2011) or have attempted to look at future academy scenarios (under status-quo policies) to gauge their ageing potential (Feichtinger et al. 2007; Leridon 2004; Matthiesen 1998; van de Kaa and de Roo 2008). However, each of these studies has focused on only one academy (e.g. the Austrian, French, Royal Danish or Royal Dutch) and, moreover, on the consequences of one specific policy mix. In this paper, we assess the role of a more diverse set of policies aimed at regulating the size and age structure of intake in influencing the potential evolution of full membership of a broader set of academies of sciences: the Austrian, Berlin-Brandenburg, Russian and Norwegian Academies and the Royal Society of London. We first summarise the history and policies of each of the academies in our study, showing the degree of variation in policies across them. Second, we discuss the implications of different policies across these academies, regulating the number and influencing the age structure of elections, on the ultimate size and age structure of academies. Finally, we illustrate the effect of different

${ }^{3}$ This flexibility is higher relative to that of a nation state attempting to rejuvenate its population (e.g. decrease its mean age or dependency ratios) as academies can control inflows (and, arguably, their age structure) more efficiently. Moreover, the potential of age-structured inflow (i.e. net immigration) as a solution to population ageing in nation states is quite limited (Coleman 2002; Espenshade 2001; Schmertmann 1992; United Nations 2001).

${ }^{4}$ Academies refer to this age as that of 'retirement'. However, members past this age generally retain full rights and privileges in the academy (many undoubtedly keeping very active research agendas, whether still employed by their academic employers or not given retirement rules in places like Norway), thereby rendering the term 'retirement age' somewhat meaningless in the context of effective academy membership. 
policies on ageing by contrasting the steady-state and transient dynamics of different projections of full members (hereafter FM) in each academy into 2070 and measuring the size and age-compositional effect of enacting a given policy vis-à-vis a standard policy scenario. Our comparative study ultimately aims to provide a more general assessment of the effect of various age-graded recruiting policies on the size and age structure of other organisations. We finally discuss some of the implications of our study for the literature on how to regulate the pace of ageing on the nation-state scale through age-structured immigration.

\section{The Academies and their policies}

\subsection{Brief portraits of the Academies}

We base our comparisons between different election policies on data from historical membership records (up to 2005) of five European learned societies: the Austrian Academy of Sciences, the Berlin-Brandenburg Academy of Sciences, the Royal Society in London, the Russian Academy of Sciences and the Norwegian Academy of Sciences and Letters. We use first-hand data provided by the respective academy and membership registers published either online (The Royal Society 2005; Russian Academy of Sciences 2008; Berlin-Brandenburgische Akademie der Wissenschaften 2009) or in hardcopy (Russian Academy of Sciences 1999; Amundsen 1957; Helsvig 2007; Hittmair and Hunger 1997; Österreichische Akademie der Wissenschaften 1996-2005) as well as from Andreev and Jdanov (2007). The size and age structure of full membership varies considerably across academies (see Table 1, Figure 1) and can be explained by variation in intake rates, the age structure of new members (Figure 2), and - to a lesser extent-by the mortality conditions to which members are exposed to (Jdanov and Andreev 2009; Winkler-Dworak 2011).

The Austrian Academy of Sciences (OEAW), founded in 1847, limits the number of members below a statutory 'retirement' (henceforth SR) age of 70 years (since 1972, 75 years in 1950-1971) to 45 in each of its two sections: Mathematics and the Natural Sciences, and Humanities and the Social Sciences (Feichtinger et al. 2007). Despite the total number of FMs below that age thus being limited to 90 , the actual size of the academy as of mid-May 2005 (just after elections took place) was 164, as 45 per cent of FMs were over age 70 . New members need to have Austrian residence and stellar academic records, and they generally come from the ranks of Corresponding Members (henceforth, CMs). Only the Austrian and Russian academies have such a 'candidate' status, which might partly explain their older ages at election as will be explained below. 
Table 1

Summary of history, policies, and membership and age structure (as of January 2005) of academies

\begin{tabular}{|c|c|c|c|c|c|}
\hline 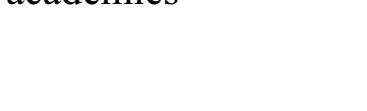 & Austrian & $\begin{array}{c}\text { Berlin- } \\
\text { Brandenburg }\end{array}$ & Russian & $\begin{array}{l}\text { Royal } \\
\text { Society }\end{array}$ & Norwegian \\
\hline Year of foundation & 1847 & 1700,1993 & 1724 & 1660 & 1857 \\
\hline Data availability & $1847-2005$ & $1700-2005$ & $1724-1999$ & $1660-2006$ & $1950-2005$ \\
\hline $\begin{array}{l}\text { Status previous to full } \\
\text { member? }\end{array}$ & Yes & Until 1993 & Yes & No & No \\
\hline $\begin{array}{l}\text { Current maximum } \\
\text { intake }\end{array}$ & N/A & N/A & N/A & 44 & N/A \\
\hline $\begin{array}{l}\text { Statutory retirement } \\
\text { (SR) age }\end{array}$ & 70 & 68 & N/A & N/A & 67 \\
\hline Current maximum size & 90 & 200 & N/A & N/A & 219 \\
\hline $\begin{array}{l}\text { Current full } \\
\text { membership }\end{array}$ & 164 & 173 & 496 & 1,257 & 459 \\
\hline $\begin{array}{l}\text { Per cent FMs above } \\
\text { 'retirement' age }\end{array}$ & 45.1 & 2.3 & N/A & $\mathrm{N} / \mathrm{A}$ & 52.3 \\
\hline
\end{tabular}

The Berlin-Brandenburg Academy of Sciences (BBAW) was founded, strictly speaking, only in 1993, though some of its members had previously belonged to the roster of the old Prussian Academy, which became the German Academy of Sciences in Berlin in 1946 and was renamed Academy of Sciences of the German Democratic Republic in 1972 (Berlin-Brandenburgische Akademie der Wissenschaften 2009). In the wake of German reunification, the academy was closed in 1992 and re-constituted in 1993 with the new name. Upon 're-foundation', the Academy dropped the Corresponding Member status, enacted a retirement age of 68 and established a limit of 200 members below the statutory retirement age. However, as of early 2005, membership under the SR age was still well below the limit, namely at 169 . The whole full membership of the BBAW sums up to 173 (Table 1), making those above the SR age only 2.3 per cent of total membership.

The Russian Academy of Sciences (RAS) lacks a statutory retirement age and does not have any clear limits for the number of elections, which take place every three years (unlike the other academies where elections occur annually). As of mid-2005, there were 496 FMs, by and large elected from a pool of corresponding members. Despite having one of the highest growth rates and lowest life expectancies among academies (Jdanov and Andreev 2009; Winkler-Dworak 2011), the Russian academy has the oldest observed age structure: 68 per cent of their members are above age 70 . This is due to the fact that newly elected members tend to be much older than those in other academies: the mean age at election in the 15 years prior to 2005 was around 61 , roughly 4 years older than in any of the other four academies (Figure 2).

Like in the Russian case, the Royal Society lacks a statutory retirement age or any membership size limits per se (in addition, it lacks a corresponding member category). 
Although the RS does limit the number of elected fellows (to 44 per annum in 2004), ${ }^{5}$ this intake is large enough (relative to the total membership) to result in high growth in the latter half of the 20th century (Figure 3), making the RS the largest academy of the five societies hereby studied, with membership standing at 1,257 in mid-2005 (Table 1). Such high growth has indeed resulted in a younger age structure as compared to that of the Austrian and Russian academies, but not compared to the still young group of academicians from Berlin-Brandenburg (Figure 1).

\section{Figure 3}

Full membership size by academy and year

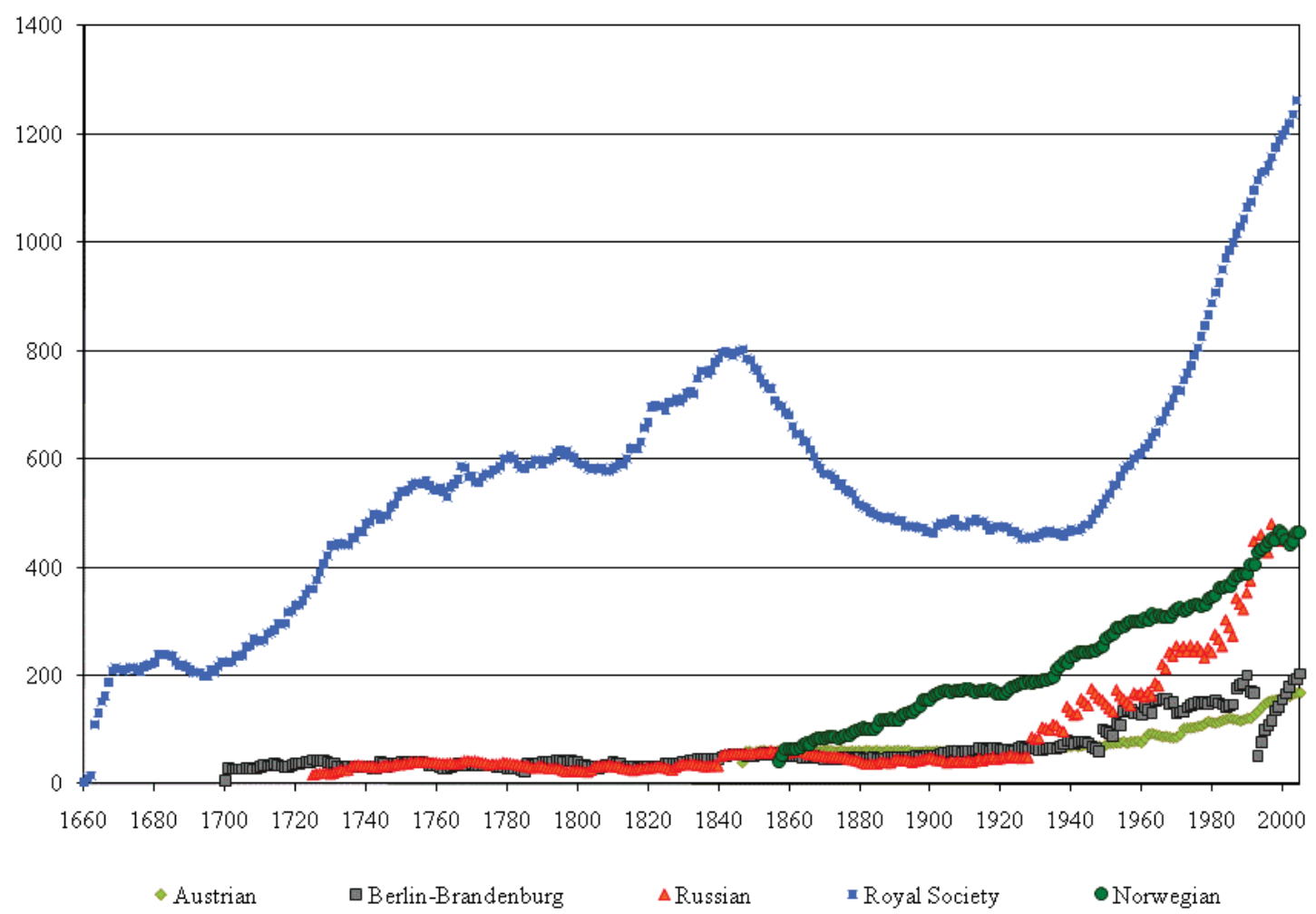

The Norwegian Academy of Sciences and Letters, with a similar mean age as the Royal Society (Figure 1) does not have a corresponding member status either but does have a statutory retirement age of 67 (in line with Norwegian law for any member of the labour force). As in the Austrian and Berlin-Brandenburg cases, membership size below the SR age is limited (in this case to 219 members). However, the total size of the academy is 459 , implying that 52 per cent of its members are older than the SR age, a percentage similar to the one observed in the Austrian academy.

\footnotetext{
1980.

${ }^{5}$ These limits increased from 15 in the early 1900 s to 25 around mid-century, reaching 40 around
} 


\subsection{Intake policies and their implications in the ageing of learned societies}

In the previous section we showed there is considerable variation regarding the size, number of elections and age structure of the five academies. Although 'exogenous' conditions - such as mortality and the relative size of the pool of potential academicians (in turn affected by various supply and demand factors beyond the scope of this paper) are at play, a narrow set of intake (i.e., election) policies under the potential (or actual) control of the academies also affect the size and age structure of these organisations. We focus on two such policies. One - whether an academy has fixed or linked intake - affects the growth and size of the academy. The other-whether academies have a corresponding, or candidate, membership status - may influence the age structure of elections (i.e. shift it to the right with a corresponding status), which in turn affects the age structure of full members. We describe both policies in more detail next and study their long-run implications, i.e. their role for the stable age distribution.

\section{Policies affecting intake size: limiting and linking the number of elections}

Although rapid population ageing can be 'alleviated' by rapid growth, this is not a feasible policy for learned societies as they are generally highly selective institutions. Academies limit the number of full members to be voted in a given election period in two main ways. First, they may select a fixed number of new members per election period, as in the case of the Royal Society. In the long run, any population (academy) with a fixed (age-specific) inflow (elections) and constant mortality schedule will eventually become stationary (Espenshade et al. 1982; Arthur and Espenshade 1988; Schmertmann 1992). The steady state of the population, however, could be much larger/smaller than the initial one depending on the age structure of intake (Arthur and Espenshade 1988) because of momentum (Keyfitz 1971; Kim and Schoen 1997; Preston et al. 1989; Rowland 1996). Before reaching a steady state, the population will experience a transitory growth (decline) phase if the crude rate of intake (in this case, the ratio of elections to number of members) is higher (lower) than the crude death rate. Note that this occurs partly because the crude death rate is in turn affected by the initial age structure of the academy during the pretransitional period.

Alternatively, intake per election period (typically, annually) could be linked to a given amount. ${ }^{6}$ As mentioned above, the Austrian, Berlin-Brandenburg and Norwegian academies have set the number of elections to match the number of people reaching a 'statutory retirement' age, which is currently at 70, 68 and 67 years, respectively. This has fixed the number of full members below the SR age limit to 90 in Austria, 200 in BerlinBrandenburg, and 219 in Norway (though, as members past this age generally retain all their rights and privileges as full members, this policy has not limited the de facto size of the academy).

As in the case of fixed intake, linked age-specific intake and a fixed mortality schedule does eventually lead to a stationary population (both below and above the

\footnotetext{
${ }^{6}$ For a similar assumption applied to general populations, see Alho (2008) and Liao (2001).
} 
retirement age) as the number of open vacancies eventually stabilises to a fixed number. As such, the age structure of elections is a crucial determinant of future vacancies (i.e. elections) and membership size (e.g. the younger the newly elected members are, the longer it takes until the members reach the SR age limit in order to open new vacancies). In other words, there is a clear trade-off between the age structure of members and the number of elections (Dawid et al. 2009; Feichtinger et al. 2007; Feichtinger et al. 2011).

For both fixed and linked intake, the initial age structure of the population may be an important consideration when deciding which type of intake policy to enact as it could drive the pre-transitional dynamics of the academy (i.e. momentum could be non-trivial). Before discussing if academies might be better off with either policy based on the results from our macro-simulations, we discuss policies that may affect the age structure of intake as well.

\section{Corresponding membership and other policies affecting the age distribution of elections}

In addition to any policy directly aimed at regulating the age distribution of elections some policies may indirectly affect the age structure of learned societies. Academies such as the Austrian, the Russian and - until 1993 - the Berlin-Brandenburg one have had a 'corresponding membership' status with more limited rights and privileges (most notably, these members have no voting rights). Historically, corresponding membership has served different purposes, such as recognising the work and maintaining links with scientists living abroad (or outside of the area of influence of the academy), who were thus not eligible for full membership due to residence requirements in academy byelaws. In many academies, corresponding membership has also served as candidate pool for the election of full members, although the byelaws of academies with a corresponding membership status do not explicitly state that full members should be elected from the pool of corresponding members or any other membership category.

The existence of a candidate status can affect the age distribution of elections in two ways. First, even if all CMs were elected into full membership, the size and age distribution of corresponding members would set constraints to the pool of people that can become full members. Although this restriction is relaxed by the fact that not all CMs get elected as FMs, the transition from CM to FM seems to be a function of age and also - to some extent - age at election as CM. To illustrate this, Table 2 shows estimates of lifetime probabilities of being promoted from $\mathrm{CM}$ to $\mathrm{FM}$ in Austria for those elected as CM between 1960 and 1990. The probability of becoming a FM was lower the older academicians were when elected as CM. Transition probabilities ranged from 88 per cent for (the few) members elected before their 46th birthday to 38 per cent for those elected as $\mathrm{CM}$ after age 55 (probabilities decrease monotonically for the age groups in-between). Thus, if most members are elected from the ranks of $\mathrm{CM}$ and their ages at election as $\mathrm{CM}$ signal the strength of their records and potential for being elected as FM, then the age structure of FM intake is a function of and, as such, is constrained by the age structure of CMs. 


\section{Table 2}

Probability of ever becoming a full member, mean duration before FM election, and mean age at election as FM in the Austrian Academy of Sciences by age and period of election as corresponding member, members elected as CM in 1966-1990.

\begin{tabular}{l|c|c|c}
$\begin{array}{l}\text { Age at election as } \\
\text { Corresponding Member } \\
\text { (CM) }\end{array}$ & $\begin{array}{c}\text { Raw probabilities of ever } \\
\text { becoming a Full Member } \\
\text { (FM) }\end{array}$ & $\begin{array}{c}\text { Mean duration as CM } \\
\text { for those who became } \\
\text { FMs }\end{array}$ & $\begin{array}{c}\text { Mean age at } \\
\text { election as FM }\end{array}$ \\
\hline Less than 45 & 0.872 & 8.0 & 49.6 \\
45 to 49 & 0.792 & 8.1 & 55.7 \\
$50-54$ & 0.764 & 6.0 & 58.4 \\
55 and over & 0.378 & 4.6 & 64.6 \\
\hline All ages & 0.629 & 6.7 & 57.3
\end{tabular}

Perhaps as a result, full membership might be attained later than otherwise, i.e. without a candidate status. In Figure 2 above, we showed the mean age at election as FM in the five academies under study by period. It is rather clear that not only has age at election increased over time, but it is considerably higher in the two academies with a corresponding status previous to full membership (Russia and Austria) despite their contrasting policies regarding the number of elections (in Russia, high, non-fixed intake; in Austria, linked intake). Age at election as FM may be higher in academies with CM status because it 'allows' academies to elect members to an intermediate status before they (potentially) achieve full membership or may simply add more time to the waiting process for potential academicians.

While we do not model a two-stage election process (CM and FM) explicitly (see Feichtinger et al. 2011 for a model), we do look at different scenarios considering the effect of changes in the age structure of intake on the age structure and ultimate size of both fixed- and linked-intake regimes. In other words, we assume that the existence of a $\mathrm{CM}$ status implies an older age structure of intake or, at the very least, consider different scenarios regarding the age structure of intake.

Note that changing the age structure of intake will not only alter the steady-state age distribution of an academy but also its size, and that the direction of this effect will be contingent on the type of intake. An older age structure of intake will of course make an academy older than it would otherwise be under a younger election schedule (Schmertmann 1992), regardless indeed of intake type as we show in our analyses below. However, a younger or older age structure of intake will also have consequences on the ultimate size of an academy because the age structure of elections will influence the momentum observed in the academy. In academies with a fixed intake, a younger age structure of elections will imply a larger stationary size of the academy due to fewer deaths (see also Arthur and Espenshade 1988).

In contrast, the momentum of an academy under linked intake will be more complex inasmuch as a younger age structure of election may imply a smaller membership size in the steady state. On the one hand, a younger age structure of elections implies a longer 
waiting time before those members reach the SR age, implying a lower number of vacancies in the academy (Dawid et al. 2009; Feichtinger et al. 2007). On the other hand, the younger the age structure of election, the fewer deaths will be observed implying a larger membership size of the academy. Which effect will dominate depends, ceteris paribus, on the initial age structure of the academy. But note that, most definitely, the ultimate size of an academy will be quite different under linked as compared to fixed intake even when using the same age structure of elections.

Next, we describe our strategy aimed at illustrating the extent to which the combination of the type of intake and the age structure of new members affect the size and age structure of full membership. We also note that the initial shape of the age structure in each academy (i.e. the past history of intake policies and practices and of mortality) have an important effect in determining the ultimate size of the academy under a new regime of intake policies.

\section{Comparing academies' transient and ultimate size and age structure under different policies}

In order to understand the effect of different policies and practices regarding intake type and the age structure of elections on the academies' size and age structure, we project each academy to 2070 using cohort-component projections (e.g. Preston et al. 2001, Chapter 6). While this allows us to study the steady-state age structure in each regime, we also compare the ultimate size of different scenarios for each academy in order to understand how pre-transitional dynamics (e.g. momentum) vary by scenario and according to initial conditions in each academy. To avoid conflating the effects of policies (or initial conditions) and those of differential mortality across academies (Jdanov and Andreev 2009; Winkler-Dworak 20011), we standardise longevity conditions for all academies by using a standard mortality scenario used previously by Feichtinger et al. $(2007, \text { p. } 23)^{7}$ until 2050 , after which we maintain mortality conditions to be fixed (at 2050 levels) until 2070.

We manipulate two main policies in our scenarios: intake type (linked vs. fixed) and the age distribution of elections (status quo vs. standard). We present results from three scenarios for each academy (except the Austrian, as is explained below). First, the status quo scenario assumes academies to have followed the same intake type they currently practice with an age structure of elections based upon a smoothed version of the academy-specific age distribution of election in the 1990-2004 period (the number of elections is based on recent numbers for fixed-intake academies as well). Figure 4 shows the smoothed status quo age distribution of election in each.

\footnotetext{
7 The mortality scenario assumes the same mortality development as in the latest forecast of death probabilities by Statistics Austria (Hanika and Klotz 2005), which were derived using the Lee-Carter method (Lee and Carter 1992). As Academicians show a significantly lower mortality than the general population, the forecasted death rates were adjusted according to the standardised mortality ratio for the most recent period (for more details see Feichtinger et al. 2007).
} 


\section{Figure 4}

Age distribution of elections in status quo and standard scenarios by academy

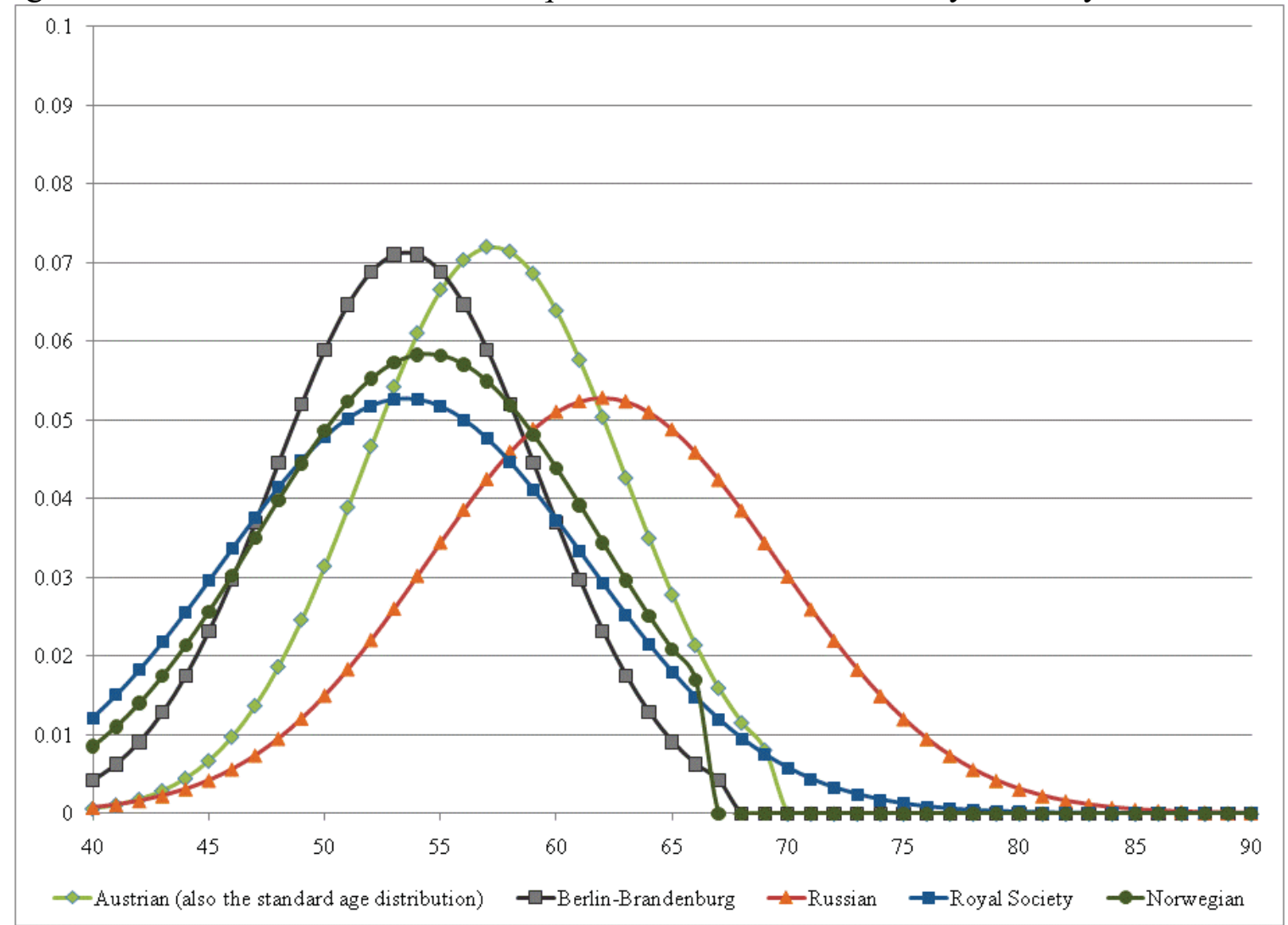

The second scenario uses the same status quo age structure of elections but the opposite intake policy to the one currently observed (i.e. from fixed to linked intake or vice versa). The third scenario uses the status-quo intake policy while standardising the age structure of elections. We use the Austrian Academy of Sciences' age distribution as our standard. Note that this standard age structure is younger than that of the Russian academy and older than that of the Berlin-Brandenburg and Norwegian Academies as well as the Royal Society's and it is less dispersed than for the other academies except the BerlinBrandenburg Academy, which shows a similar variance as the standard. As the standard chosen is that of the Austrian academy, we do not present the latter scenario for this academy as it is of course exactly the same as the status quo projection.

Note that some of these policy scenarios required additional assumptions. First, although the Russian Academy of Sciences has no clear limits on the number of elections in recent years, we specified the number of elections in its status quo scenario to 42 elections per year (the average on the 15 years prior to our baseline) to facilitate comparisons with other academies and policies. Second, when going from fixed to linked intake, we chose a SR age of 70 and fixed the size below this age to 750 in the case of the Royal Society and 300 in the case of the Russian Academy of Sciences. ${ }^{8}$ The number of

\footnotetext{
${ }^{8}$ In the case of the Royal Society, this number is close to the number of members below age 70 at baseline thereby tying its future growth to its pace of ageing. In the case of the Russian Academy of Sciences, we allowed it to grow from its baseline membership below age 70 of $\sim 200$ to 300 as fixing it at 200
} 
vacancies (elections) under the new linked regime is not fixed but corresponds to the number of members that turned 70 that year plus the number of deaths occurring before age 70 (an only minor figure due to the low mortality of academicians). Moreover when changing the intake policy from fixed to linked elections, we also had to truncate and rescale the status quo distribution of age at elections so no FM elections take place after 70 in the status quo calculations. Finally, going from linked to fixed intake requires specifying the annual number of elections: we set the number of elections for these academies (Austrian, Norwegian and BBAW) to the average number of elections in the 15 years prior to our initial year (i.e. in the 1990-2004 period), equal to 7 in the Austrian Academy of Sciences, 15 in the Berlin-Brandenburg Academy of Sciences and 17 in the Norwegian Academy of Sciences and Letters.

\subsection{Effect of intake policy}

Table 3 shows results for each scenario in terms of (A) academy size, (B) number of elections per year, (C) mean age of academy members, (D) the standard deviation in the mean age of the members of the academy and (E) the proportion of members below age 70. We present these figures at initial, medium-run and steady-state conditions as reflected by the values of these quantities in 2006, 2025 and 2070. Regarding size (Panel A), going from linked to fixed intake (that corresponds to levels equal to the average number of elections per period in 1990-2004) in the Austrian, Norwegian and Berlin-Brandenburg cases implies growing stronger in the pre-transitional period (ultimate size is 6.6 per cent higher in the first two academies and 14 per cent higher in the latter) than in the status quo scenario. The number of elections (which are equal to the number of open vacancies below the SR age, see Panel B) are higher in the short run in the status-quo than in the fixedintake scenarios but then stabilise to a similar or slightly lower level than the average number of elections in 1990-2004 used in the fixed-intake scenario. Note that the short-run growth is exceptionally high in the Berlin-Brandenburg academy as they had not met its stipulated limit of 200 members below age 68 by 2005 .

would have implied a very sizable dip in the number of academicians of all ages in the steady state given that the academy age structure is considerably older than that of the other academies (and as such, the implied number of elections in the linked-intake scenario would have plummeted relative to the status-quo scenario). Note, however, that even setting this number to 300 implied a moderate amount of negative momentum for the Russian Academy. We discuss this below. 


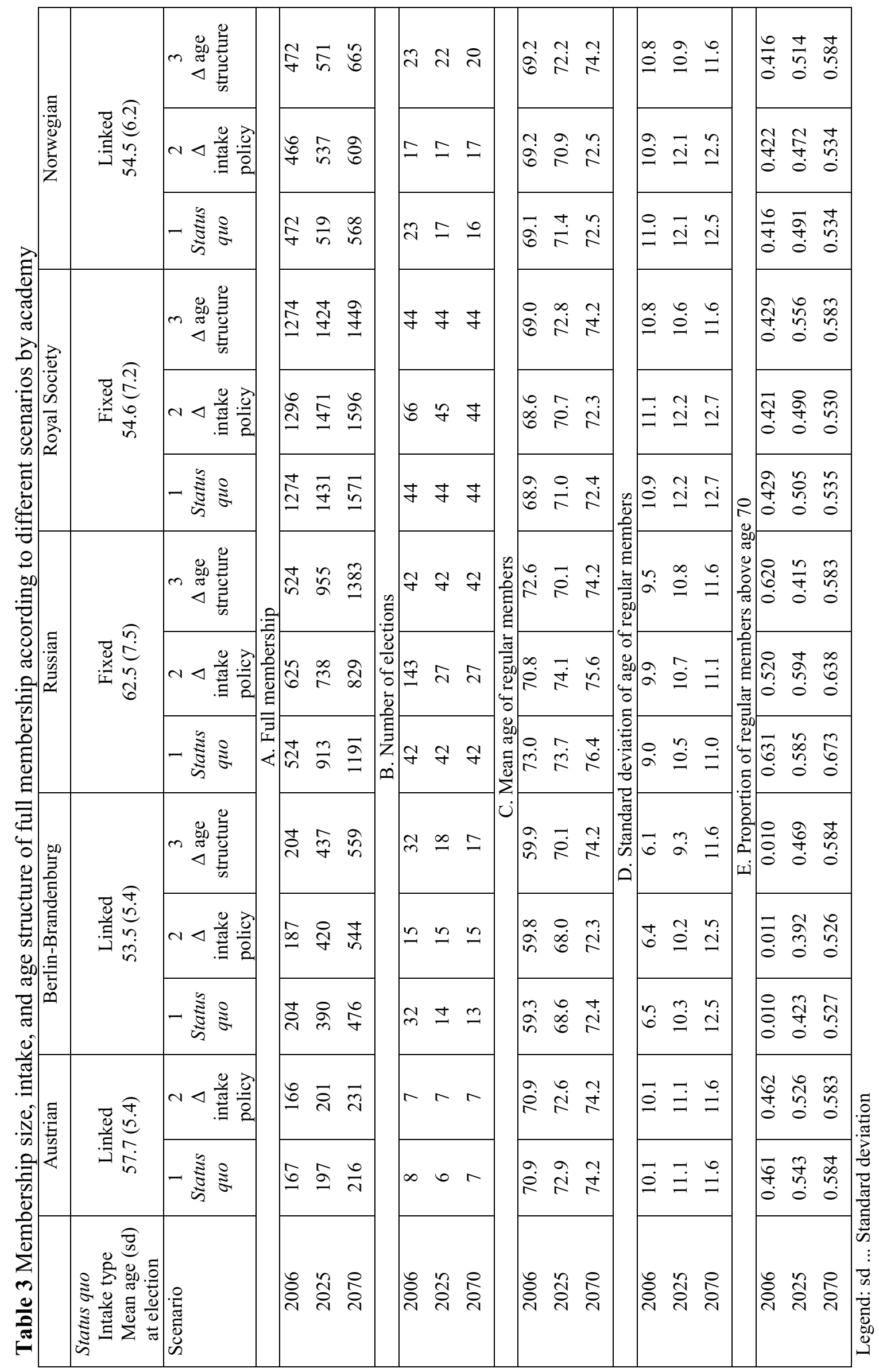


Transitioning from a fixed- to a linked-intake type of election (scenario 2 in Table 3) implies a lower average number of elections in the projection period and thus a smaller membership size for the Russian Academy of Sciences: its steady-state size under fixed intake would be 1,191 members while under linked intake the stationary size would be only 829 . While one would expect that a relatively old age structure of intake, such as the status-quo distribution of elections in the Russian Academy of Sciences, implied a large number of elections given the trade-off between number of elections and age structure of members at election under linked intake (Dawid et al. 2009), the large difference in ultimate size between these two scenarios is the result of negative momentum (Rowland 1996). That means, as the percentage of Russian academicians who are above age 70 is rather large (63 per cent, see Panel E), the projected number of deaths is well above the projected number of newly-elected members. Note that this is true even though, in the linked-intake scenario, we set the number of academicians below the SR age to 300, a number well above the number of members below age 70 at baseline (158). As such, our estimate of negative momentum is quite conservative relative to that of enacting a policy setting the number of members below the SR age close to the status quo at baseline (as we do in the case of the Royal Society). Only if we increased the maximum size of the academy under age 70 to almost triple the number of members below 70 in 2006 (results not shown) would these differences vanish.

In contrast, the Royal Society would grow slightly less rapidly under its current policy of fixed intake, projected to be 1,571 by 2070 than by linking the number of elections to those reaching age 70 , projected to 1,596 . This is due to the fact that the recent past of a large number of elections under a young age structure of intake resulted in a favourable age structure of members in 2006 allowing a considerable amount of growth in the short run as these relatively large cohorts come close to 'retirement' age. Coincidentally, the ultimate number of elections under the linked intake is the same as the fixed-intake number of elections.

Remarkably, changing intake policies while keeping the age structure of elections constant has no consequences regarding the ageing prospects of academies in the long run: regardless of initial conditions, academy size and intake type, the same age-specific distribution of intake and mortality schedules results in the same age structure for all (i.e. one with a mean age of 74.2 years and a standard deviation of 11.6 years around the mean, where 58.35 per cent of members are above age 70; see Panels C, D, and E for scenario 3 in all academies, Table 3). Hence, choosing between a policy that fixes or anchors the number of elections with the same age distribution will affect the stationary size but not the stationary age structure of an academy. As we base our parameter assumptions on the recent past history of the academies in terms of number of elections and age structure of members, the growth rates under fixed or linked type do not differ substantially. As long as the latter holds, the stationary age structure is independent of the type of intake because of ergodicity (Lopez 1967). Nevertheless, the number of elections could vary considerably during the pre-transitional period due to momentum (Keyfitz 1971). 


\subsection{Effect of age structure at election}

Scenario 3 in Table 4 presents the results for each academy with the status-quo type of election but standardising for the age structure at election. Obviously, an older (younger) age structure of intake implies that the steady-state age structure of the academy will be older (younger). That means that using the standard age distribution at election implies a younger ultimate age structure of members for the Russian Academy of Sciences and an older age structure of members for the other learned societies (see Panels C, D and $\mathrm{E}$ in Table 3, Scenario 3). Again, the ultimate age structure is solely determined by the age distribution at election and independent from initial conditions or intake type: standardising for the age distribution at election, the age structure of members for all academies eventually converges to the same age structure, which is characterised by a mean age of full members of 74.2 years, a standard deviation of 11.6 years around the mean and a proportion of members below age 70 equal to 58.4 per cent.

Note that a lower dispersion of the age at election in the standard scenario compared to the status quo implies also a lower ultimate dispersion of age of members except for the Russian Academy of Sciences (see Panel D in Table 3). While the standard deviation of the status-quo age distribution of the Russian Academy is about two years larger than the standard deviation of the standard age distribution, the steady-state standard deviation of the status quo is actually slightly lower than the one of the standard age distribution for the Russian Academy of Sciences. The latter results can be explained by the higher ages of members in the status-quo scenario for the Russian Academy of Sciences and the fact that mortality increases with age, implying a more left-skewed age structure of members compared to the standard scenario.

The implications of standardising the age structure at election on the size and number of elections do indeed hinge on the type of intake. Under fixed intake, the pretransitional growth implications of standardising the age structure of elections (as reflected in the steady-state size of the academy) are contingent on whether the status quo distribution is older/younger than the standard of course: ceteris paribus, a younger distribution of elections will yield a larger steady-state academy than an older age distribution (see also Arthur and Espenshade 1988). For the Russian Academy, where the status quo age structure of intake is older than the standard, electing 42 younger members per year with the younger standard age structure would result in a larger stationary size (1,383; see Scenario 3, Table 3) than electing 42 academicians with the older status quo age structure (1,191; see Scenario 1, Table 3). In the Royal Society, going from electing 44 members with a younger status quo age distribution to electing the same number of members with the older standard intake schedule (the opposite direction of the change in Russian academy) would imply attaining a slightly smaller academy in the steady state (1,571 vs. 1,449; Scenarios 3 and 1, respectively, Table 3). In both cases, this is a result of a higher pre-stationary transitional growth under a younger age structure as a result of lower crude death rates.

As mentioned before, the effect of a younger or older age structure of elections on the stationary size of academies with linked-intake regimes is not as straightforward as in fixed-intake academies where deaths are the only component of growth depending on how young or old the age structure of elections is. Under linked intake pre-transitional 
dynamics of the academy are more complex as the transient and steady-state number of elections is also contingent on the age structure of intake. Moreover, unlike the number of deaths, which are directly proportional to mean age at election, the number of vacancies is inversely proportional to mean age at election (Dawid et al. 2009; Feichtinger et al. 2007). This is so because a younger age structure of intake will extend the expected waiting time before statutory retirement, thus implying a lower number of vacancies in the medium and long run (Feichtinger et al. 2007). On the other hand, a younger age structure of elections will imply a lower death flow in the medium run.

Which of these two effects dominates (and thus, if a linked-intake policy implies a larger or a smaller stationary size than one of fixed intake) depends on initial conditions, as these will determine the transient election and death flow. In both linked-intake academies in which we modify the age structure of elections, the effect of the age structure of elections on the number of open vacancies in the future is stronger than its effects on the death flow. In the Norwegian Academy, the older standard schedule yields a larger number of elections (20 vs. 16) and a larger population size (665 vs. 568) than the status quo scenario. Likewise, in the Berlin-Brandenburg Academy of Sciences, the older standard age structure of intake yields both a larger stationary number of elections (17 vs. 13) and a larger academy size (559 vs. 476) than in the status quo scenario.

\section{Discussion}

In this paper, we have shown the importance of different intake policies (in terms of fixed vs. linked intake and with respect to the age structure of intakes) on the intrinsic stationary size and age structure of academies of sciences using data from five academies with a mix of heterogeneous policies/practices (Table 1). We have found that the stationary age structure is solely determined by the age structure at election and independent from the type of intake. Thus the age structure of elections becomes the key policy variable to regulate both the pace of ageing in the academy and the future number of vacancies in the case of linked intake. The choice of one intake policy over the other is then a matter of deciding (1) how large an academy should be in the long run and (2) what would be an acceptable set of conditions (e.g. number of elections) in the medium run.

Most obviously, a younger age structure of inflow implies a younger stationary age structure in academies with either type of intake (Table 3, Panels C, D, and E; see also Schmertmann 1992). The solution to academy ageing, however, is not as simple as electing a younger set of new members, not only because their age may already be reasonably 'young' as far as selecting prestigious scientists goes but because the stationary size of a population is sensitive to the age structure of intake (Panel A in Table 3, see also Arthur and Espenshade 1988). As academies are selective institutions, they may not prefer rapid growth for the mere sake of rejuvenation. Nevertheless, academies have enacted policies in order to increase their statutory membership size several times throughout history in order to, among other objectives, incorporate new directions in science and rejuvenate their member population. 


\section{What then is the optimal strategy?}

The effect of the age structure of inflow on the stationary size of an academy further depends on the type of intake. A younger inflow implies a larger stationary size in academies under fixed inflow (i.e. the Royal Society and the Russian Academy of Sciences). In academies under linked inflow, this effect is not unequivocal as explained above. However, in the two cases we studied here (e.g. the Norwegian and BerlinBrandenburg academies), a younger age structure of elections implied a smaller stationary size. Thus, if academies and other organisations cared about curbing their growth and pace of ageing, linked intake would seem to be a better solution than setting the number of elections to a fixed number.

Assuming these are the objectives of an organisation and having established that linked intake will tend to outperform fixed intake in terms of academy size (while having the same effect on the stationary age distribution), the question then lies in how to optimise the trade-off between the number of open vacancies and their age distribution that yields the youngest academy while electing as many members as possible. Feichtinger and colleagues (Dawid et al. 2009; Feichtinger et al. 2007) have shown that a bimodal distribution of elections is the optimal strategy among all linked-intake scenarios.

Having said that, our projections of the Russian Academy of Sciences highlight the relevance of initial conditions in the subsequent transient dynamics of academies adopting a policy of linked intake. Linked intake only seems like a reasonable strategy if the recent history of the academy has not implied both high growth and ageing by way of electing many older members. Otherwise, academies should be aware that the transient dynamics and ultimate size will be especially sensitive to enacting this policy. In the Russian case, interrupting the history of rapid growth (Figure 1) and an older election schedule (Figure 4) would imply a most dramatic drop in the ultimate stationary population to levels well below the initial size of the population (Table 3, Panel A) given that most members in the initial population are already above the assumed SR age (Table 1). In short, academies should thus consider their recent demographic history before deciding to enact specific policies as the transient growth and ageing dynamics and ultimate size of the academy will also depend on them.

Our study also contributes to the literature on how age-structured intake may affect ageing in populations. Most other studies have dealt with questions on how to regulate ageing in nation states through age-structured immigration (e.g. Liao 2001; Feichtinger and Steinmann 1992; Schmertmann 1992; United Nations 2001; Wu and Li 2003), if at all possible (Coleman 2002). While these studies have proposed solutions with regard to how to minimise ageing in the context of a stationary population, they did not quite deal with the additional restriction of considering how large the steady-state population would be. Our study suggests that linking the number of immigrants to a given number (e.g. as a proportion of the number of births, see Alho 2008) while considering a bi-modal age structure based on labour market considerations could potentially minimise the pace of ageing at the same time as achieving a smaller steady state than one under a fixedmigration scenario with the same age structure. Future research should look at the potential effect for these kinds of age-structured intake on the ageing and size of nation states at large. 


\section{References}

Amundsen, L. 1957. Det norske Videnskaps-Akademi i Oslo 1857-1957. I Kommisjon hos H. Aschehoug \& Co., Oslo.

Andreev, E. M. and Jdanov, D. A. 2007. Prodolzhiteĺnost́ zhizni: chem boĺshe znaem, tem doĺshe zhivem? [in Russian] (Life expectancy: the more we know the longer we live?) Foresight, vol. 3, no. 3, pp. 49-52.

Alho, J.M. 2008. “"Migration, Fertility, and Aging in Stable Populations“. Demography, vol. 45 , no. 3 , p.641.

Arthur, W.B. and T.J. Espenshade. 1988. "Immigration Policy and Immigrants' Ages". Population and Development Review, vol. 14, no. 2, pp. 315-326.

Berlin-Brandenburgische Akademie der Wissenschaften. 2009. Mitglieder der BerlinBrandenburgischen Akademie der Wissenschaften und Mitglieder der Vorgängerakademien [Online], Berlin-Brandenburgische Akademie der Wissenschaften, Available from: $<$ http://www.bbaw.de $>$ [Accessed in March 2009].

Bongaarts, J. 2009. "Human population growth and the demographic transition". Philosophical Transactions of the Royal Society B: Biological Sciences, vol. 364, no. 1532, pp. 2985.

Cohen, J.E. 2009. "The Demography of the Resident Membership of the American Philosophical Society". Proceedings of the American Philosophical Society, vol. 153, no. 2, pp. 200-213.

Coleman, D.A. 2002. "Replacement migration, or why everyone is going to have to live in Korea: a fable for our times from the United Nations'. Philosophical Transactions of the Royal Society of London. Series B: Biological Sciences, vol. 357, no. 1420, pp. 583.

Dawid, H., G. Feichtinger, J.R. Goldstein, and V.M. Veliov. 2009. "Keeping a learned society young". Demographic Research, vol. 20, no. 22, pp. 541-558.

Espenshade, T.J. 2001. “'Replacement Migration' from the perspective of equilibrium stationary populations". Population and Environment, vol. 22, no. 4, pp. 383-389.

Espenshade, T.J., L.F. Bouvier and W.B. Arthur. 1982. "Immigration And The StablePopulation Model”. Demography, vol. 19, no. 1, pp. 125-133.

Feichtinger, G. and Steinmann, G. (1992). Immigration Into A Population With Fertility Below Replacement Level - The Case Of Germany. Population Studies-A Journal Of Demography, vol. 46, no. 2, pp. 275-284. 
Feichtinger, G., M. Winkler-Dworak, I. Freund, A. Prskawetz and F. Riosmena. 2007. "On the Age Dynamics of Learned Societies: Taking the Example of the Austrian Academy of Sciences". Vienna Yearbook of Population Research 2007, pp.107-131.

Feichtinger, G., A.A. Krasovskii, A. Prskawetz and V.M. Veliov. 2011. "Optimal agespecific election policies in two-level organizations with fixed size". European Journal of Operations Research. Published Online First: 13 March 2011. doi: 10.1007/s10100-0110197-4

Hanika, A. and J. Klotz. 2005. Personal correspondence.

Helsvig, K. G. 2007. Elitisme på norsk: Det Norske Videnskaps-Adademi 1945-2007. Novus Forlag, Oslo.

Hittmair, O. and Hunger, H. 1997. Akademie der Wissenschaften: Entwicklung einer österreichischen Forschungsinstitution. Verlag der Österreichischen Akademie der Wissenschaften, Wien.

Houdaille, J. 1980. Mortalité dans divers groupes et notables du XVIIème au XIXème siècles. Population, no. 4-5, pp.966-968

Jdanov, D.A. and E. Andreev. 2009. "Higher Education and Lower Mortality: Longevity in the Russian Academy of Science and the Royal Society". in XXVI IUSSP International Population Conference. Marrakech, Morocco.

Keyfitz, N. 1971. "Momentum of Population Growth”. Demography 8(1):71-80.

Kim, Y.J. and R. Schoen. 1997. "Population momentum expresses population aging". Demography, vol. 34, no.3, pp. 421-427.

Lee, R.D. and L.R. Carter. 1992. "Modeling and forecasting US mortality". Journal of the American Statistical Association, vol. 87, no. 419, pp. 659-671.

Leridon, H. 2004. "The demography of a learned society: the Académie des Sciences (Institut de France), 1666-2030”. Population, vol. 59, no. 1, pp. 83-116.

Leridon, H. 2005. The demography of a learned society. The Académie de Sciences (Institut de France), 1666-2030. Paper presented at the Workshop on "The Demography of Learned Societies', Vienna, 30 November 2005.

Liao, T.F. 2001. "How Responsive is U.S. Population Growth to Immigration? A Situational Sensitivity Analysis”. Mathematical Population Studies, vol. 9, pp. 217-229.

Lopez, A. (1967). "Asymptotic Properties of a Human Age Distribution under a Continuous Net Maternity Function”. Demography, vol. 4, no. 2, pp. 680-687.

Matthiessen, P. C. 1998. "A demographic analysis of RDASL membership". In A. Kuijsten, H. de Gans \& H. de Feijter (Eds.), The joy of demography ... and other 
disciplines. Liber amicorum presented to Dirk van de Kaa on the occasion at this retirement as Professor at the University of Amsterdam (pp. 355-360). Amsterdam: Thela Thesis.

Österreichische Akademie der Wissenschaften. 1996-2005. Almanach. Verlag der Österreichischen Akademie der Wissenschaften, Wien. 146.-155. Jahrgang.

Preston, S.H., C. Himes and M. Eggers. 1989. "Demographic conditions responsible for population aging”. Demography, vol. 26, no.4, pp. 691-704.

Prskawetz, A., D.E. Bloom and W. Lutz. 2008. Population aging, human capital accumulation, and productivity growth: Population Council.

Rowland, D.T. 1996. "Population momentum as a measure of ageing". European Journal of Population, vol. 12, no. 1, pp. 41-61.

Russian Academy of Sciences. 1999. Russian Academy of Sciences: List of the Academy Members, 1724-1999. Nauka, Moscow.

Russian Academy of Sciences. 2008. Resources search: Personal list since RAS foundation [Online], Russian Academy of Sciences, Available from $<\underline{\mathrm{http}}$ ://www.ras.ru/win/db/home.asp? $\mathrm{P}=\ln -\mathrm{en}>$ [Accessed in March 2008].

Schmertmann, C.P. 1992. "Immigrants Ages and the Structure of Stationary-Populations with Below-Replacement Fertility". Demography, vol. 29, no. 4, pp. 595-612.

The Royal Society. 2005. List of fellows of the Royal Society, 1660-2007.[Online], The Royal Society, Available from: <http://royalsociety.org> [Accessed in March 2006].

Uhlenberg, P. 2009. International handbook of population aging. Amsterdam: Springer Verlag.

United Nations. Dept. of, E. and D. Social Affairs. Population. 2001. Replacement Migration: Is it a Solution to Declining and Ageing Populations? United Nations.

Van de Kaa, D.J. and Y. de Roo. 2008. "De leden van de Koninklijke Nederlandse Akademie van Wetenschappen - een demografisch perspectief: 1808 tot 2008”, KNAW Press, Amsterdam.

Winkler-Dworak, M. 2008. "The Low Mortality of a Learned Society". European Journal of Population, vol. 24, no. 4, pp. 405-424.

Winkler-Dworak, M. 2011. "The Mortality of Learned Societies: an International Comparison". Unpublished manuscript.

Wu, Z. and N. Li. 2003. "Immigration and the Dependency Ratio of a Host Population." Mathematical Population Studies, vo. 10, pp. 21-39. 


\section{VIENNA INSTITUTE OF DEMOGRAPHY}

\section{Working Papers}

Buber, Isabella and Katrin Fliegenschnee, Are you Ready for a Child? A Methodological Triangulation on Fertility Intentions in Austria, VID Working Paper 03/2011.

Fent, Thomas, Belinda Aparicio Diaz, and Alexia Prskawetz, Family Policies in the Context of Low Fertility and Social Structure, VID Working Paper 02/2011.

Buber, Isabella, Caroline Berghammer, and Alexia Prskawetz, Doing Science, Forgoing Childbearing? Evidence from a Sample of Female Scientists in Austria, VID Working Paper 01/2011.

Strulik, Holger, Klaus Prettner, and Alexia Prskawetz, R\&D-Based Growth in the Post-Modern Era, VID Working Paper 09/2010.

Prettner, Klaus and Alexia Prskawetz, Demographic Change in Models of Endogenous Economic Growth. A Survey, VID Working Paper 08/2010.

Flandorfer, Priska, Christian Wegner, and Isabella Buber, Gender Roles and Smoking Behaviour, VID Working Paper 07/2010.

Barakat, Bilal, Johannes Holler, Klaus Prettner, and Julia Schuster, The Impact of the Economic Crisis on Labour and Education in Europe, VID Working Paper 06/2010.

Grafeneder-Weissteiner, Theresa and Klaus Prettner, Agglomeration Processes in Ageing Societies, VID Working Paper 05/2010.

Buber, Isabella, Parity-specific weights for the Austrian Generations and Gender Survey, VID Working Paper 04/2010.

Testa, Maria Rita, She wants, he wants: Couple's childbearing desires in Austria, VID Working Paper 03/2010.

Buber, Isabella, Wissenschaftlerinnen in Österreich - Zusatzerhebung im Rahmen des GGS.Dokumentation der Datenerhebung und deskriptive Ergebnisse, VID Working Paper 02/2010.

Kuhn, Michael, Stefan Wrzaczek, Alexia Prskawetz, and Gustav Feichtinger, Externalities in a Life-Cycle Model with Endogenous Survival, VID Working Paper $01 / 2010$.

The Vienna Institute of Demography Working Paper Series receives only limited review. Views or opinions expressed herein are entirely those of the authors. 